\title{
Integrated Mobile Veld Fire Detection and Notification System for Rural Communities: A Case of South Africa, Zimbabwe and Namibia
}

\author{
Taruvinga Amon, Chikohora Edmore, Jere Nobert, and Dool Riaan
}

\begin{abstract}
Socio-economic and environmental impacts of veld fires are acknowledged, documented and widely discussed at different forums. However, what is largely missing are solutions to reduce occurrence of veld fires mostly in rural areas. Literature also suggests that veld fires are to increase (more intense and long burning) with warming (hot and dry conditions - climate change). This is likely to affect rural poor households who largely depend on land-based natural resources (field crops, forests harvest, grazing land); with limited access to fire brigades, that mainly serves urban cities. With warming (drier and hotter conditions), rural areas who share boundaries with mountains, rangelands, forests and wetlands are predicted to face greater threats from veld fires because of the dry flammable biomass in these areas. Against these drawbacks and leveraging high mobile phones ownership and network coverage in rural areas, we present an integrated mobile application for veld fire detection and notification prototype rural households can use to identify high fire danger areas and burning fires in near real time close to their location.
\end{abstract}

Index Terms-Mobile phones, rural communities, veld fires.

\section{INTRODUCTION}

Veld fires are widely viewed as an essential management tool in rangelands [1]. For example, Savannas are fire-driven systems despite associated negative impacts that may arise. Burning also positively influences soil organic matter and nutrient availability [2]. Thus far, managed fires may be used strategically for ecological benefits. However, the challenge is not on managed fires but on unmanaged veld fires. Unmanaged veld fires may; alter soil properties, reduce ecosystem productivity, alter plant species diversity and structure [3], increase soil erosion, destroy properties, plantations, field crops, kill humans, livestock and wildlife and negatively affects functioning of many ecosystems [2], [4], [5]. Unmanaged veld fires are very popular in rural areas and are predicted to increase with climate change - warming [6]. Equipping rural communities with modern user-friendly technologies that can identify burning fires in near real time and notifying them of the fire danger index of their area will therefore go a long way towards reducing incidences of

Manuscript received September 13, 2019; revised December 11, 2019.

A. Taruvinga is with the University of Fort Hare Private Bag X1314 Alice South Africa (e-mail: ataruvinga@ufh.ac.za).

E. Chikohora is with the Namibia University of Science and Technology Private 13388, Windhoek, Namibia (e-mail: echikohora@nust.na).

N. R. Jere is with the Walter Sisulu University P.O Box 1421, East London, 5200, South Africa (e-mail: njere@wsu.ac.za).

R. van den Dool is with CSIR, PO Box 395; Pretoria 0001, South Africa (e-mail: rvddool@csir.co.za). unmanaged veld fires. This paper presents a mobile application for veld fire detection and notification prototype. The prototype can be used by; local authorities, environmental management organizations, farmers, parks and forestry departments to monitor unmanaged fires in their properties and fire danger index for their area.

\section{A. Problem Statement}

Negative impacts of veld fires are widely acknowledged especially in rural Africa [2], [4], [5], [7]. Limited local efforts to manage veld fires in these areas are also reported mainly faced with many technical and institutional challenges [8]. Among other things, poor property rights in most rural Africa presents a huge threat for conservation of common pool natural resources like forests, rangelands, mountains and wetlands. Unfortunately, veld fires in rural areas normally emanates from such common pool natural resources. They are therefore largely ignored by default (lack of technologies that can identify these fires and alert residents) and by choice (tragedy of the commons). We therefore argue that, in the absence of advanced technologies and poor environmental institutional frameworks veld fires are likely to perpetuate and worsen in rural Africa.

\section{B. Objective}

To develop a veld fire detection and notification system using mobile phones for rural communities.

\section{Methodology}

The research adopted a mixed approach methodology; experimental, quantitative and qualitative. Most activities followed the participatory research approach, as this project required a bottom-up approach knowledge sharing and co-designing. The study therefore considered experimental designs, surveys and focus group discussions. Within that holistic stakeholder interaction the study co-identified challenges faced by rural communities from Namibia (Khomas Region - Windhoek), Zimbabwe (Mashonaland West Province) and South Africa (Matatiele Local Municipality) concerning veld fires. A shared desired future (reduced veld fire occurrence in rural areas) and a shared sustainable transformational process (pathway) that can reduce incidences of veld fires was agreed upon. A purposive convenient sampling procedure (based on availability and willingness to participate) was considered focusing on rural households and veld fire management institutions from areas with high incidences of veld fires as reported in the past 15 20 years. We conducted a community - based assessment to 
get an insight of the communities' current livelihood and natural resource governance. Ownership and sustainable transformation can only take place within a participatory development approach from the onset. Therefore, community surveys were performed to assess the communities' governance structures, livelihood activities, as well as needs and skills related to natural resources management including veld fire management. Overall, a community-based co-design (CBCD) methodology was applied to the development of the joint sustainable veld fire management, the community governance structures and the technologies to be integrated in the final mobile veld fire App. This methodology was established based on long-term development collaborations with indigenous communities in Namibia, Zimbabwe and South Africa, as well as a theoretical framing in the local concept of Ubuntu and Afrocentricity. This is based on principles of participation as promoted in participatory design, participatory rural appraisal, and participatory action research among many other similar research and development approaches. Therefore community members were treated as project partners with local expertise rather than being just informants or service providers and later receivers of technology.

\section{RESULTS AND DISCUSSION}

This section describes the results of the study more focusing on the prototype architecture, functionalities, compatibility with rural users and its operation for a typical rural local municipality.

\section{A. Challenges Faced by Veld Fire Stakeholders}

A majority of the stakeholders noted the following challenges: (a) poor to almost missing veld fire identification systems in rural areas, (b) lack of knowledge on daily fire danger index of rural areas and (c) poor coordination during veld fires. These challenges are widely reported in literature [7], [8].

\section{B. Preferred Veld Fire Notification System}

Fig. 1 presents preferred mode of communication for veld fire notifications as suggested by veld fire stakeholders from the study areas.

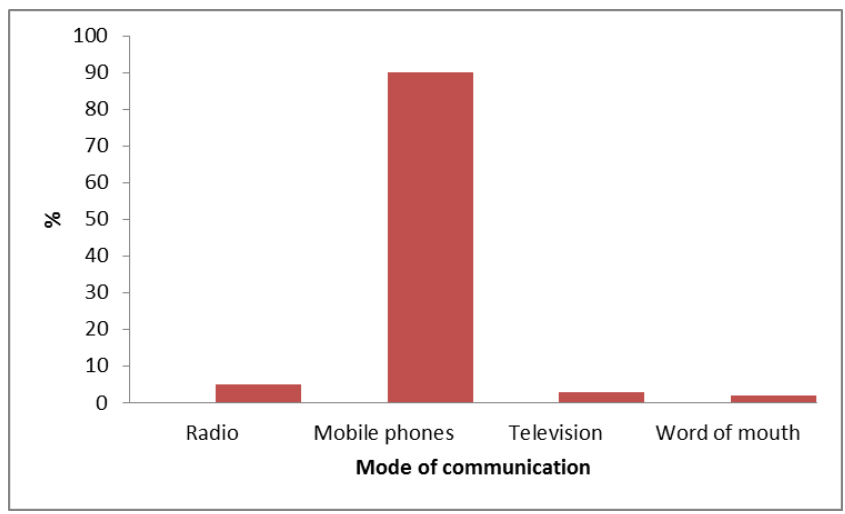

Fig. 1. Preferred mode of communication for veld fire notifications.

Results reveal high preference of sharing veld fire notification using mobile phones $(90 \%)$. A majority of these stakeholders especially from rural areas had access to basic phones [9] in areas where internet coverage is very poor. The agreed transformation pathway was therefore to develop an integrated mobile application for veld fire detection and notification compatible with basic phones using SMS but more preferably with a voice option in native language. The following sections summarize the developed application.

\section{Description of the AFIS}

The Advanced Fire Information System (AFIS) is a wildfire information system, developed and operated by the CSIR, that integrates satellite and camera based fire observations with local weather station and forecast information to provide a comprehensive solution to predict, detect, monitor and assess wildfire incidents.

\section{Mobile Veld Fire Architecture}

The mobile veld fire architecture consists of the backend and the front functionalities. The architecture is based on the following technologies that make up the key architecture components: Global Positioning Systems (GPS), Application Programmable Interfaces (API), CoreLocation (Mapkit) and SMS Gateway (Clickatell). Each of these components performs its own functionality, which supports the overall architecture performance. The Global Positioning Systems (GPS) is responsible for the following: user location tracking, region monitoring, entering and exiting regions, user, and veld fire proximity alert. The Application Programmable Interfaces (Wunderground API) provides the following architectural services: query weather data, weather forecast, storm, location specific data, local, national, international, acquire weather reports and hourly, monthly, yearly weather historical data. The CoreLocation (Mapkit) is responsible for: identifying user location on a map, define veld fire regions on a map and to monitor entry and exit of regions. Then finally, the SMS Gateway (Clickatell) provides the following functionalities: send messages, warnings, alerts, news, receiving messages and sending back feedback.

The architecture also has both technical considerations and the development process. The technical considerations included the following requirements:

- Developed on Macintosh OS (Operating Systems)

- Developed using XCode IDE (Integrated Development Environment)

- Developed using Swift 2 programming language

- Developed for iPhone and iPads

The development process was as follows:

- Application flow layout: pages, views and navigation.

- Interface design (look and feel) using CoreLocation (Mapkit) as the center of the design.

The development process was guided by the key functionality that the system provides. These are summarized as the main functionalities offered from the mobile veld fire architecture:

- Query Wunderground API and create region-using data,

- Map Wunderground API data used on google maps (Mapkit),

- Track user location in and out of regions,

- Monitor proximity and veld fires and initiate notification alerts, 
- Predict veld fire using climate data patterns from Wunderground using veld fire models,

- Send messages of current and potential fires.

\section{E. Prototype Functionalities}

Daily fire danger index notification functionality: Fire danger indices give residents an opportunity to understand the risk level of veld fires in their area. This can be used as an opportunity to alert residents not to start fires when the index is high and to be alert for possible veld fires in their area. Most unmanaged fires start as managed fires, started when the fire danger index is high. This daily fire danger index notification functionality acts as an early warning awareness for residents.

Using the Advanced Fire Information System's (AFIS) fire danger index models, if the application detects high probability of an area to start veld fires, the application will send early warning veld fire awareness messages to mobile phones of residents of that specific area. Against this background we therefore argue that if residents are aware of the fire danger index of their area, they are more likely to avoid starting managed fires if the fire danger index is high.

Veld fire identification and notification functionality: The second functionality identifies all burning fires in near real times. Veld fires in most rural areas frequently occur unnoticed especially when they start in forests, mountains, rangelands and wetlands or during the night. By the time they are noticed they would have destroyed the environment and very huge to control. Public knowledge suggests that it is easy to control or stop veld fires when they are starting (when they are small) than when they have burnt a larger area (when they are huge).

Thus far, an application that can identify burning fires on occurrence and notify residents closer to the burning fires will make it easier for the control of veld fires and save the environment. Using the AFIS' live fire system, if the application identifies burning fires, it sends messages to residents of that specific area burning. We therefore argue that all burning fires will be identified in their early stages and more likely to be managed before destroying the environment.

\section{F. Other AFIS Functionalities That Can Also Be Accessed by End Users}

Fire spread functionality: AFIS allows a user to request a fire spread simulation at a specific point through its web application user interface. The result of the simulation provides a prediction of the spread and flame length based on weather parameters, topography and fuel (vegetation) types.

Burned areas functionality: AFIS also provides historic information for areas burned over the period 2002 to present. The burned area information is updated monthly and is presented as a burn sum (burn frequency) and a days since last burn data layer.

\section{G. System Compatibility with Rural Users}

Mobile network coverage has recently improved in most rural areas of Africa [9]. Despite this improvement in mobile network coverage, $3 \mathrm{G}$ and $4 \mathrm{G}$ services are still very poor in most rural areas of Africa. Guided by the above facts, the prototype was designed to accommodate basic network services common in most rural areas. This was possible through leveraging SMS with a voice option in local language to cater for the illiterate. Residents with basic phones will therefore need to register their lines for them to receive the alerts and notifications. Those with advanced phones, they can either register or just download the App.

\section{H. How the System Operates for a Typical Local Municipality / Rural District Council}

In this section, we describe how the system operates using a typical local municipality - Matatiele, Eastern Cape Province South Africa as illustrated in Fig. 2 and Hurungwe rural District Council - Zimbabwe as illustrated in Fig. 3. Most local municipalities have local management structures that spans down to village levels. There are also several institutions that govern veld fire management at local level. The prototype is therefore designed to enhance operations of these institutions not substituting them, for the actual management of veld fires is handled by them.

For a typical local municipality, the first stage would be to demarcate the entire local municipality into $5 \mathrm{~km}$ radius polygons or less depending on the terrain of the area as illustrated in Fig. 1. Each polygon (coded V1 to V63) will host one or more villages. Village veld fire fighters are identified who could be village heads. Several polygons also make up wards of a local municipality. Ward veld fire fighters are also identified who could be ward councilors. A data base of; a) village veld fire fighters' mobile phone numbers synchronized with each polygon's coordinates, b) ward veld fire fighters' mobile phone numbers synchronized with specific ward polygons' coordinates and c) local municipality veld fire institutions' mobile phone numbers synchronized with the entire local municipality's polygons coordinates is created.

Linking the village, ward and local municipality veld fire fighters' coordinates and mobile phone numbers to the notification system will enhance area specific reporting of fire danger indices and identified live fires. Thus, village veld fire fighters will only receive notifications specific to their polygon, while ward veld fire fighters will receive notifications specific to polygons defining their wards.

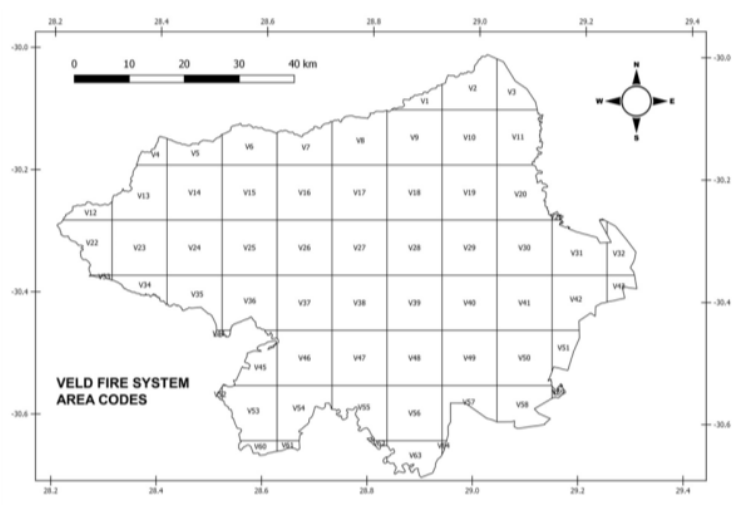

Fig. 2. Veld fire system area codes for Matatiele Local Municipality.

Local municipality veld fire institutions (fire department, municipality, police, etc.) will receive notifications for the entire municipality.

Fig. 3 presents a summary of how the system operates at rural district level. 


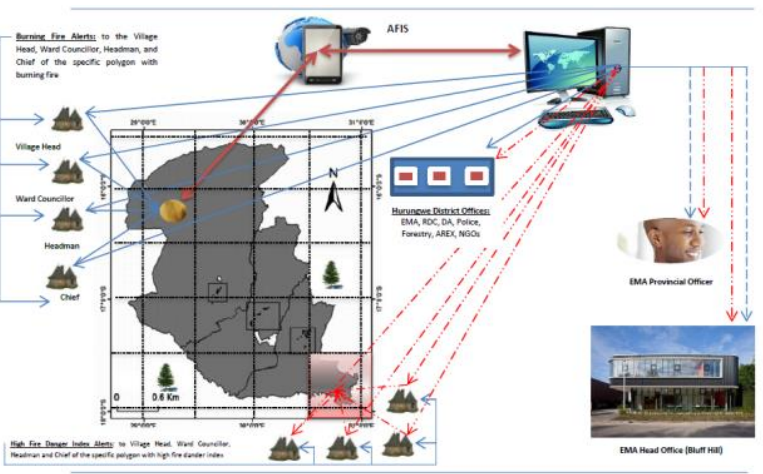

Fig. 3. Mobile veld fire detection, monitoring and sharing at district level.

Reading from the AFIS the prototype will notify residents, district, provincial and national veld fire stakeholders connected to system daily fire danger indices for different wards defining a district. If veld fire is identified anywhere in the district any time of the day by the AFIS, registered residents $5 \mathrm{~km}$ radius from the burning fire will receive SMS notification of the fire with coordinates and nearby geographical features. Ward councilors and traditional leaders of the burning area will also receive the burning fire alert even if they are outside the $5 \mathrm{~km}$ radius. District, provincial and national veld fire stakeholders will also receive these alerts as illustrated in Fig. 3.

Fire spread simulation summarizing a prediction of the spread and flame length based on weather parameters, topography and fuel (vegetation) types can be provided to enhance strategic planning by fire fighters on site. Lastly, monthly-burned area per ward, district, province, country and region can be provided to veld fire stakeholders for planning purposes.

\section{Potential Application Users}

The application can be used by several stakeholders to include; local municipalities, district councils, farmers, game parks and plantations. Although designed for areas with poor internet coverage where basic phones will be used, a version of the application for smartphones in areas with good internet coverage is also available. Those with advanced phones, they can either register or just download the App (which shall be available on the App Store).

The following screenshots (Fig. 4 - 7) summarizes how the App operates from home page to alerts.

Fig. 4 summarises the App icon and home page as viewed from a smartphone. Fig. 5 summarises the application settings. Firstly, users can set veld fire warnings and alerts at regional or national level as illustrated in the first panel of Fig. 5. Secondly, users can also preselect specific area they wish to receive warning and alerts messages as illustrated in the second panel of Fig. 5. Lastly, users can zoom their map to their specific area of choice. They can also preselect number of days in future they wish to see the predicted climatic conditions, the radius from their preferred location they wish to receive veld fire alerts and warnings and their preferred notification system (sms, email and social media) as illustrated in the third panel of Fig. 5.

Fig. 6, first and second panels summarises the notification methods users can opt for to receive alerts and early warning messages. In the last panel, if the user selects for example Nyanga a pop-up message summarising the current weather for the area appears with exact coordinates and 7 days predicated weather summarised on hourly basis per day.

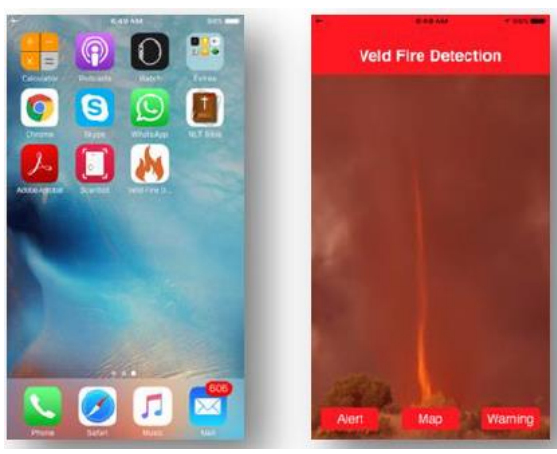

Fig. 4. Application icon and home page views Source: Jere, Scott and Taruvinga (2017)

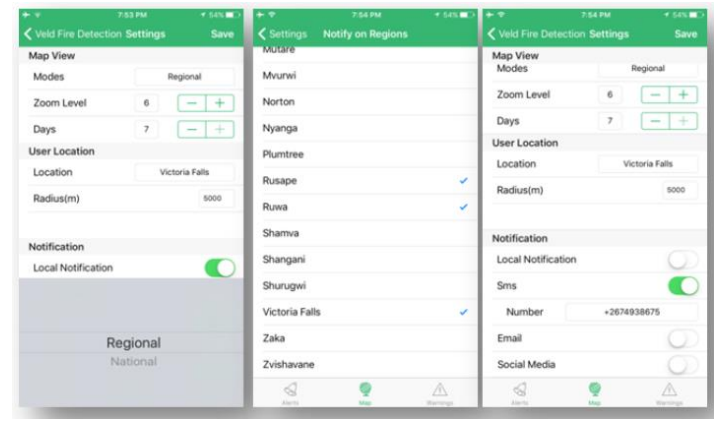

Fig. 5. Application setting pages.

Fig. 6 summarises further settings on the application.

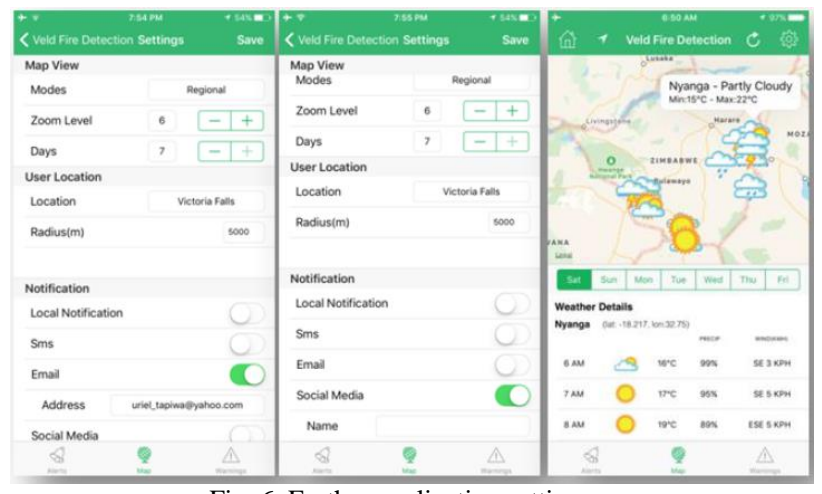

Fig. 6. Further application setting pages. Source: Jere, Scott and Taruvinga (2017)

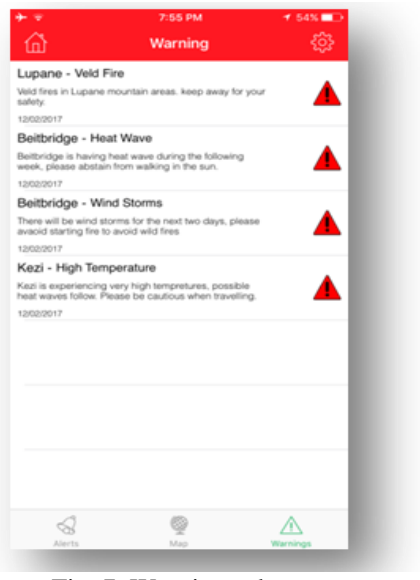

Fig. 7. Warnings alert page.

Source: Jere, Scott and Taruvinga (2017) 
Fig. 7 presents the warnings alert page.

If veld fires are predicted to occur based on local fire danger index for a specific area in the country, early warning alerts are send to mobile phones of registered residents of that specific area, warning them not to engage in actives that cause fire and to be alert in case fires starts in their area. In the event of a burning fire in the area, registered users will also receive notification messages informing them of the exact location of the fire.

The interesting part of the App is its ability to personalise alerts and notifications. Users can pre-set the App to focus on a specific area of their choice (say their farm, homesteads) and its radius. Once they are online wherever they are (say attending meetings / workshops away from their area or even abroad in other countries) they can still receive veld fire alerts and notification for their properties.

\section{CONCLUSION}

The paper presents a mobile phone veld fire identification and notification application for basic and smartphones, which can be used in rural areas with limited internet coverage and areas with strong internet coverage. The paper therefore concludes that by leveraging ICT most veld fires can be identified regardless of their location anytime in their early burning stages for notification to veld firefighting stakeholders closer to the fire. Also area specific risk level of high fire danger index can be identified and shared with residents of that area on daily basis for awareness purposes. Fire spread simulation can also be shared to enhance strategic planning by fire fighters on site.

\section{CONFLICT OF INTEREST}

The authors declare no conflict of interest.

\section{AUTHOR CONTRIBUTIONS}

All authors participated equally during the following stages of the paper development: conception, methodology, results and discussion, editorial work. All authors have approved the final version.

\section{ACKNOWLEDGMENT}

We acknowledge the following institutions for financing this project: National Research Foundation - South Africa (NRF) \& National Commission on Research Science and Technology - Namibia (NCRST). We also acknowledge the Council for Scientific and Industrial Research - South Africa (CSIR) our research partner for the Advanced Fire Information System (AFIS).

\section{REFERENCES}

[1] M. I. Magomani and J. J. van Tol, "The impact of fire frequency on selected soil physical properties in a semi-arid savannah Thornveld," Acta Agriculturae Scandinavica, Section B-Soil \& Plant Science, vol. 69 , no. 1, pp. 43-51, 2019.

[2] B. Muqaddasa, X. Zhoua, T. Lewisb, C. Wilda, and C. C. Chen, "Long-term frequent prescribed fire decreases surface soil carbon and nitrogen pools in a wet sclerophyll forest of Southeast Queensland, Australia," Science of the Total Environment, vol. 536, pp. 39-47, 2015.
[3] I. T. Little, P. A. R. Hockey, and R. Jansen, "Impacts of fire and grazing management on South Africa's moist highland grasslands: A case study of the Steenkampsberg Plateau, Mpumalanga, South Africa," Bothalia, vol. 45 , no. 1 , p. 15,2015

[4] N. R. Jere, M. S. Scott, and A. Taruvinga, "An integrated mobile veld fire detection and sharing platform for Southern Africa," in Proc. SAICSIT '17, Thaba Nchu, South Africa, September 26-28, 2017, p. 7, 2017.

[5] M. Alcañiz, L. Outeiro, M. Francos, and X. Úbeda, "Effects of prescribed fires on soil properties: A review. Sci Total Environ,” pp. 613-614, 944-957, 2018.

[6] W. Maluleke and R. J. Mokwena, "The effect of climate change on rural livestock farming: Case study of Giyani policing area, Republic of South Africa," South African Journal of Agricultural Extension, vol. 45, no. 1, pp. 26-40, 2017.

[7] E. Dube, "Improving disaster risk reduction capacity of District Civil Protection Units in managing veld fires: A case of Mangwe District in Matabeleland South Province, Zimbabwe," Jàmbá: Journal of Disaster Risk Studies, vol. 7, no. 1, p. 13, 2015.

[8] M. N. Wiggill, "Communication management during the veld fires of 23 August 2011 in the Tlokwe Local Municipality: A cautionary tale," Jàmbá: Journal of Disaster Risk Studies, vol. 5, no. 2, p. 9, 2013.

[9] GSMA's Mobile Economy, The Mobile Economy, Sub-Saharan Africa, Press Release, GSMA Press Office David Ntwampe Maila, 2018.

Copyright $\odot 2020$ by the authors. This is an open access article distributed under the Creative Commons Attribution License which permits unrestricted use, distribution, and reproduction in any medium, provided the original work is properly cited (CC BY 4.0)

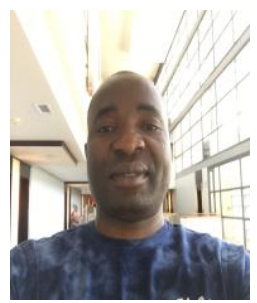

Amon Taruvinga was born in Zimbabwe. $\mathrm{He}$ received his BSc (Hons) degree in agricultural economics from the University of Zimbabwe and his $\mathrm{PhD}$, also in agricultural economics, from the University of Fort Hare, South Africa. He is currently an associate professor in the Department of Agricultural Economics and Extension at the University of Fort Hare, South Africa. Prof Taruvinga specializes in environmental economics, human wildlife interactions, food security, climate change and smallholder agriculture. $\mathrm{He}$ is interested in promoting sustainable human-wildlife interaction.

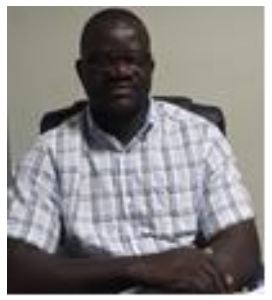

Edmore Chikohora was born in Zimbabwe. He received his BSc (Hons) degree in information systems from Midlands State University, Zimbabwe and his $\mathrm{PhD}$ in computer science from North West University, South Africa. He is currently a senior lecturer in the Department of Informatics at Namibia University of Science and Technology. He is interested in image processing, evolutionary computing, ICT and agriculture.

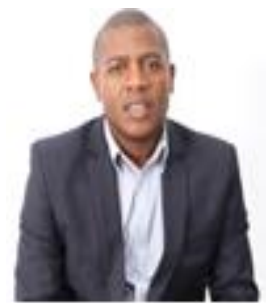

Nobert Jere was born in Zimbabwe. He received his BSc (Hons) degree in information systems from Midlands State University, Zimbabwe and his PhD in computer science from University of Fort Hare, South Africa. He is currently a senior lecturer in the Department of Information Technology at Walter Sisulu University, South Africa. He is interested in emerging technologies in agriculture, mobile applications development.

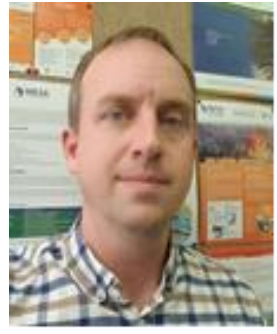

Riaan van den Dool was born in Cape Town, South Africa and received his MSc Eng degree in electronic engineering and computer science from the University of Stellenbosch, South Africa. He is currently a senior engineer at CSIR and is responsible for the development and operations of the Advanced Fire Information System (AFIS). He is interested in remote sensing, wildfire information systems and application of technology to support decision making and conservation 